\title{
EL DICTAMEN DE LA COMISIÓN DE GRAMÁTICA (1861) DE LA REAL ACADEMIA ESPAÑOLA Y SU REPERCUSIÓN EN LA GRAE (1870)
}

\author{
Alberto Hernando García-CERVigón \\ Universidad Rey Juan Carlos
}

1. Con la entrada en vigor, el 9 de septiembre de 1857 , de la Ley Moyano, en cuyo artículo 88 se ordena que la Gramática y la Ortografía de la Real Academia Española sean texto obligatorio y único en los centros de enseñanza pública, la Corporación compone dos adaptaciones del texto gramatical, el Epítome, para la primera enseñanza elemental, y el Compendio, para la segunda enseñanza. De acuerdo con lo preceptuado en la citada ley, en el artículo III de los Estatutos de 1859, dentro del programa del cuidado de la lengua emprendido por la Corporación, la reforma de la Gramática se impone como uno de sus objetivos inmediatos para estar a la altura de los avances llevados a cabo en la investigación científica de las naciones más adelantadas de Europa ${ }^{1}$. Se establece que en la GRAE han de adoptarse las reformas «que la experiencia aconseje» ${ }^{2}$, tomando como punto de referencia «la opinión pública, la autoridad de escritores antiguos y modernos que han cultivado con mayor tino estos estudios, y las indicaciones razonables de los profesores más celosos y experimentados» ${ }^{3}$.

${ }^{1}$ La Real Academia Española por aquellas fechas recibe un fuerte apoyo estatal. Algunos de sus miembros, incluso, ocupan altos cargos en la Administración. La situación de monopolio de que disfrutan sus tratados de Gramática en el ámbito de la educación pública, el sólido equipo que reúne en su seno y la dedicación ininterrumpida a las tareas proyectadas —inusual en períodos anteriores, dados los acontecimientos políticos, culturales, sociales o religiosos acaecidos en nuestro país (Alonso Zamora Vicente, Historia de la Real Academia Española, Madrid, Espasa Calpe, 1999, págs. 449-455)— propician que la Corporación sienta una mayor seguridad en las decisiones adoptadas en materia gramatical que en otras épocas.

${ }^{2}$ Real Academia Española, Estatutos de la Real Academia Española aprobados por S. M., Madrid, Imp. Nacional, 1859, en Dagmar Fies, «Limpia, fija y da esplendor». La Real Academia Española ante el uso de la lengua (1771-1973), Madrid, SGEL, 1989, pág. 68.

3 Real Academia Española, Estatutos..., ibíd. 
En 1860, la Real Academia Española centra sus esfuerzos en la discusión del Reglamento ${ }^{4}$, complementario de los Estatutos, y en la composición de una Gramática que mejore la existente ${ }^{5}$. Con este propósito designa una Comisión, compuesta por J. E. Hartzenbusch, A. Fernández-Guerra y Orbe y P. F. Monlau, que redacta el Dictamen de la Comisión de Gramática (1861), proyecto de reforma que precede a la edición de 1870 de la GRAE. A pesar de haber visto la luz esta obra casi en una veintena de ocasiones desde que se publicara la primera edición (1771), y haber transcurrido ciento veinte años desde que F. A. Angulo elaborara su Proyecto de Gramática $(1741)^{6}$, es el tercer proyecto de planta con el que cuentan las ediciones de la GRAE y el penúltimo con anterioridad a la publicación del Esbozo (1973). En este «detallado informe» ${ }^{7}$, los autores dan cuenta del resultado de sus conferencias y acuerdos, y proponen las modificaciones generales que consideran oportuno efectuar en la Gramática con vistas a su perfeccionamiento.

Las reflexiones de J. E. Hartzenbusch, A. Fernández-Guerra y Orbe y P. F. Monlau habían sido «tan largas y repetidas como demandaba lo difícil de la materia» ${ }^{8}$, y sus acuerdos «tan meditados como requeria el tocar á un texto oficial y obra de una Corporacion doctísima» ${ }^{9}$. Tales circunstancias llevaron a que la Comisión se «remirára mucho en sus estudios» ${ }^{10}$, pero no constituyeron un impedimento para que expusiera «llanamente su sentir» ${ }^{11}$ y propusiera lo que había «juzgado mas conveniente para la perfeccion de la obra» ${ }^{12}$. El carácter oficial de la Institución y de sus tratados, con la consiguiente responsabilidad que tiene en materia gramatical, y la repercusión de sus resoluciones para el público constituyen factores determinantes para que su principal afán sea el

${ }^{4}$ Manuel Bretón de los Herreros, Resúmen de las actas y tareas de la Real Academia Española en el año académico de 1860 á 1861, Madrid, Imprenta Nacional, 1861, pág. 5.

5 M. Bretón de los Herreros, op. cit., pág. 3.

${ }^{6}$ El Proyecto de Gramática de F. A. Angulo es el proyecto de planta de la primera edición de la GRAE. En él se establecen las directrices de la primera edición de esta. Las ediciones y reimpresiones posteriores, con las lógicas modificaciones motivadas por los cambios teóricos, metodológicos, conceptuales o terminológicos producidos por los avances de la ciencia lingüística y del sistema lingüístico en sí, son una continuación del plan propuesto por este Académico.

7 A. Zamora Vicente, op. cit., pág 362.

${ }^{8}$ Real Academia Española, Dictamen de la Comisión de Gramática, Madrid, Imprenta Nacional, 1861, pág. 3.

9 Real Academia Española, ibíd. M. Bretón de los Herreros apunta que la ardua tarea que supone la reforma de la Gramática para cualquier autor individual es mayor en el caso de la Real Academia Española «por razones que nadie ignora. Su buen nombre además y la responsabilidad que tiene contraida la obligarán á nuevas deliberaciones luégo que otra Comision sujete á su revision la nueva Gramática que á su tiempo se redactará, ateniéndose á las bases convenidas» (op. cit., pág. 5).

${ }^{10}$ Real Academia Española, Dictamen..., pág. 3.

11 Real Academia Española, ibíd.

12 Real Academia Española, ibíd. 
perfeccionamiento de la doctrina incluida en la $G R A E$, sin que las críticas a las que con seguridad va a ser sometida o cualquier otra consideración sean un inconveniente para ello.

El Dictamen, fechado el 10 de enero de 1861, es leído en las Juntas del 31 de enero y 7 de febrero. Las propuestas plasmadas en él son revisadas con detenimiento en las Sesiones Académicas de marzo, abril, mayo y junio. En octubre, concluidas las discusiones sobre los aspectos recogidos en el Dictamen y las enmiendas sugeridas por los Sres. Académicos no pertenecientes a la Comisión de Gramática, los acuerdos adoptados en pleno mediante procedimiento democrático pasan a otra Comisión, compuesta por cinco Académicos de Número, los Sres. Hartzenbusch y Monlau — autores del proyecto de reforma-, Bretón de los Herreros, Segovia y Catalina. La función encomendada a esta Comisión es redactar la Gramática reformada ${ }^{13}$. En 1868, antes de procederse a la composición definitiva de la GRAE, las nuevas objeciones y adiciones hechas a las ediciones anteriores de la Gramática son revisadas y debatidas nuevamente en Junta de Comisión, de acuerdo con lo determinado en el Dicta$m e n^{14}$. Las aprobadas son incluidas en la edición de 1870.

2. La filosofía que subyace al Dictamen es una síntesis del racionalismo de la Gramática General, del positivismo de la Gramática Comparada y del normativismo de la Gramática Tradicional. Elementos tan heterogéneos, aunque en distinto grado, también están presentes en la edición de 1870 de la GRAE ${ }^{15}$

En el proyecto de Gramática se advierte el racionalismo de la Gramática General ${ }^{16}$ sobre todo al abordarse ciertas cuestiones fundamentales, como la definición de oración o la caracterización de algunas partes de la oración (artículo, pronombre, conjunción o interjección), fundadas en criterios logicistas.

La Filología Historicista de las lenguas modernas, en boga en Europa desde principios del siglo XIX, en este momento va ganando terreno de manera paula-

13 Esta Comisión también recibe el encargo de redactar el Compendio, el Epítome y el Prontuario de Ortografía, tomando como punto de referencia la doctrina gramatical reformada (Real Academia Española, Dictamen..., pág. 16).

14 Real Academia Española, ibíd.

15 Ramón Sarmiento, «La doctrina gramatical de la R. A. E. (1870)», Revista de Filología Románica, 4, 1986 [págs. 213-224], pág. 222. Hacia 1870 se difuminan los límites fijados entre las ciencias particulares y se produce un cambio de paradigma científico. Véanse Konrad Koerner, «Towards a Historiography of Linguistics 19th and 20th century paradigms», en Herman Parret (ed.), History of Linguistic Thought an Contemporany Linguistics, Berlin \& N. York, Walter de Gruyter, 1976, [págs. 685-718], pág. 688; Sylvain Auroux, «La catégorie du parler et la linguistique», en Romantisme. Revue du dixneuvième siècle, 25/26, [págs. 157-177], pág. 159; R. Sarmiento, art. cit., pág. 214.

16 En los primeros años del siglo XIX, los miembros de la Real Academia Española están al día de la nueva corriente de filosofía lingüística, la Gramática General (Manuel Mourelle de Lema, $L a$ teoría lingüística en la España del siglo XIX, Madrid, Prensa Española, 2002, págs. 27-35). 
tina dentro de nuestras fronteras a la Gramática General, de moda en España desde comienzos de siglo ${ }^{17}$. De este hecho se da cuenta en los Estatutos de $1859^{18}$. La Real Academia Española, precisamente, abre las puertas a la revolución de los estudios lingüísticos ${ }^{19}$ con la lectura de los discursos de ingreso en la Institución de P. F. Monlau ${ }^{20}$ o de F. de P. Canalejas ${ }^{21}$, con el de J. Valera en el de contestación al del anterior ${ }^{22}$, así como con la propuesta de publicar una Gramática comparada de las lenguas neo-latinas habladas y escritas en la Península Española ${ }^{23}$.

El normativismo - mayor en este momento debido a las circunstancias favorables que redundan en beneficio de la Corporación-, propio de la Gramática de un Cuerpo literario como el que nos ocupa, se percibe, como veremos a continuación, en la misma definición del arte gramatical.

3. La primera reforma que se propone en el Dictamen es la definición de Gramática, cuestión esencial para conocer la concepción que la Real Academia tiene de la disciplina. J. E. Hartzenbusch, A. Fernández-Guerra y Orbe y P. F. Monlau subrayan la imprecisión que hallan en la plasmada en la GRAE. En su opinión, en la Gramática de una Institución tan insigne no «deben confundirse los significados de las palabras pureza, correccion, propiedad, precision, exactitud, concision, claridad, etc.» ${ }^{24}$. A su juicio, no es «el arte de hablar con pro-

17 Para más datos acerca de esta cuestión y sobre el desarrollo de la investigación lingüística en España en el siglo XIX, véase Francisco Marcos Marín, Lingüística y lengua española: introducción, historia y métodos, Madrid, Cincel, 1975, págs. 168-184.

18 Real Academia Española, Estatutos..., págs. 63-69.

19 M. Mourelle de Lema, op. cit., pág. 173.

20 Pedro Felipe Monlau, «Del origen y la formación del romance castellano», Discursos leidos ante la Real Academia Española en la recepcion publica del Ilmo.Sr.D. Pedro Felipe Monlau, Madrid, M. Rivadeneyra, 1859.

${ }^{21}$ Real Academia Española, «Discurso leido ante la Academia Española, por D. Francisco de Paula Canalejas, en su recepcion pública, el dia 28 de noviembre de 1869», Memorias de la Academia Española, II, Madrid, Imprenta y estereotipia de M. Rivadeneyra, 1870, págs. 16-88.

22 J. Valera en el discurso de contestación al discurso de ingreso en la Real Academia Española de F. de P. Canalejas (Real Academia Española, «Discurso de contestación a F. de P. Canalejas», Memorias de la Academia Española, II, Madrid, Imprenta y estereotipia de M. Rivadeneyra, 1870, [págs. 89-136], pág. 96) indica que la Gramática General poco a poco cede paso a la Gramática Comparada, una ciencia de inducción: «En el dia de hoy, la gramática general ha cedido su puesto á la gramática comparada, la cual es una ciencia de induccion, una doctrina experimental, fundada en el exámen detenido de los hechos. La gramática comparada es, pues, una ciencia tan positiva como la química ó la física».

23 En la Sesión del 23 de noviembre de 1871, los Sres. Ochoa, Fernández-Guerra, Valera y Canalejas hacen el siguiente ofrecimiento a la Corporación: «Tenemos la honra de proponer a la Academia la redaccion de una Gramática comparada de las lenguas neo-latinas habladas y escritas en la Península Española. Si la Academia se digna prestar su aprobacion al proyecto, los proponentes tendrán la honra de presentar las bases de este trabajo» (Real Academia Española, Actas, 23 de noviembre de 1871).

${ }^{24}$ Real Academia Española, Dictamen..., pág. 3. 
piedad» ${ }^{25}$ como se indica en la $G R A E^{26}$, sino «el arte de hablar conforme á reglas ó con correccion» ${ }^{27}$, es decir, normativamente. Por ello, tras las consideraciones precedentes, proponen otra formulación distinta, «La Gramática es el arte de hablar y escribir correctamente» ${ }^{28}$, que se incluye en la edición de 1870 de la GRAE y se reproduce de forma inalterada hasta la publicación del Esbozo. A renglón seguido se pone de relieve que «los fundamentos de esta corrección se hallan en la ideología y el uso» ${ }^{29}$, esto es, en el logicismo.

La misma orientación se advierte en la definición de oración recogida en el Dictamen, muy similar a la formulada por algunos ideólogos como N. Beauzée o A. L. Destutt de Tracy:

Todo acto intelectual es un juicio; todo juicio se traduce ó significa al exterior por medio de una oracion; esta no es mas que la traduccion oral de un juicio; y á la manera que en todo juicio no hay mas que ideas y una relacion entre ellas, así tampoco en ninguna oracion hay mas que palabras y una relacion entre las palabras que la constituyen ${ }^{30}$.

4. Los miembros de la Comisión de Gramática, al elaborar el proyecto de reforma, dedican gran parte de sus reflexiones al capítulo de la GRAE que consideran más importante, el titulado De las partes de la oración en general, de cuyo contexto se deduce la doctrina de la Gramática - los restantes capítulos son el desarrollo didáctico de este- y se adivina el sistema de análisis seguido en el tratamiento de cada parte de la oración. En el Dictamen se subraya lo ventajoso que resultaría explicar con mayor claridad y exactitud las nociones de palabra, de oración y de parte de la oración; de por qué algunas de ellas son variables y otras invariables ${ }^{31}$, «dando la razon de los accidentes gramaticales» ${ }^{32}$; de suprimir una declinación y unos casos o caídas ${ }^{33}$ que no existen en castella-

25 Real Academia Española, ibíd.

26 Desde la edición de 1858 de la GRAE, la Gramática es definida como el «arte de hablar con propiedad y escribir correctamente» (Real Academia Española, Gramática de la Lengua Castellana, Madrid, En la Imprenta Nacional, 1858, pág. 1). Esta definición se reproduce en los mismos términos hasta la de 1867.

27 Real Academia Española, Dictamen..., pág. 3.

28 Real Academia Española, ibíd.

29 Real Academia Española, ibíd.

30 Real Academia Española, ibíd.

31 Desde la edición de 1854 de la GRAE, las partes de la oración son divididas en declinables e indeclinables o en variables e invariables, es decir, empleando las terminologías latinizante y moderna. En la de 1870 se les aplica únicamente las denominaciones de variables e invariables.

32 Real Academia Española, Dictamen..., pág. 4.

33 El viejo debate sobre la existencia o no de la declinación en castellano, centro de interés de los Académicos en sus disertaciones hacia 1740, es retomado en el Dictamen (Alberto Hernando García-Cervigón, El grupo del nombre en la Analogía de la GRAE [1771-1917], Madrid, Editorial Complutense, 2006). En la edición de 1854 de la GRAE se indica que en nuestro siste- 
no ni en ningún otro idioma neolatino; o de no confundir las desinencias de los verbos con las flexiones verbales. En definitiva, de «asentar con mayor exactitud, claridad y método, los buenos principios del arte de hablar correctamente un idioma» ${ }^{34}$. Tales reformas son consideradas urgentes y necesarias para que la Real Academia Española se muestre «á la altura de los conocimientos gramaticales modernos, no menos que para la perfeccion de los estudios» ${ }^{35}$.

En el Diccionario de Autoridades se había indicado que la Gramática

enseña la pronunciacion de las letras, la declinacion de los nombres, la conjugacion de los verbos, la construccion de las partes de la oracion, el sonido y accento diverso de las palabras, la distincion de las vocáles y consonantes, y la orden de hablar con propriedad, pureza y policía ${ }^{36}$.

Por tanto, se ofrece una concepción cuatripartita de la Gramática en la que se encuentran incluidas la Ortografía, la Etimología, la Sintaxis y la Prosodia, las partes clásicas en la gramática medieval y que A. Nebrija asienta como canónicas en nuestra tradición. En este sentido, J. F. Val Álvaro apunta que «el redactor de la voz, aunque alterando el orden más habitual, puede considerarse

ma lingüístico los accidentes de la declinación del artículo, el nombre, el pronombre y el participio «se verifican solo en los números y en los géneros; no en los casos, como en latin, porque estos se distinguen por medio de preposiciones» (Real Academia Española, Gramática de la Lengua Castellana, Nueva edición, Madrid, En la Imprenta Nacional, 1854, pág. 2), excepto en los pronombres personales, «que varían de forma segun los casos, y señalan algunos de ellos sin el auxilio de las preposiciones» (Real Academia Española, ibíd.). En el Dictamen se aboga por su supresión. A pesar de lo manifestado desde la edición de 1854, hasta la de 1867 se incluyen los modelos de declinación del artículo, el nombre, el pronombre y el participio por respeto a la tradición y por motivos pedagógicos y de política educativa. En la edición de 1870 se subraya que en nuestra lengua empleamos preposiciones para establecer las relaciones que en latín se llevan a cabo mediante los casos. Por ello, de acuerdo con lo propuesto en el proyecto de Gramática, en el texto de esta edición de la GRAE es suprimida la declinación, tildada de «inútil» (Real Academia Española, Gramática de la Lengua Castellana, Nueva edicion, corregida y aumentada, Madrid, Imprenta y estereotipia de M. Rivadeneyra, 1870, pág. 7), pues «sólo en el Pronombre nos queda un rastro de ella» (Real Academia Española, Gramática..., 1870, pág. 8). En la de 1874 vuelve a ser incluida. En las Nociones Preliminares de esta edición se apunta que, al denotar los casos en griego o latín «la funcion ideológica, el oficio de cada palabra en la oracion» (Real Academia Española, Gramática de la Lengua Castellana, Madrid, Imprenta y fundicion de Manuel Tello, 1874, pág. 20), tal variación se da mediante alteración de desinencias o por la adición de preposiciones. De este modo se justifica su inclusión, enseñándose que existen «casos en castellano y en todas las lenguas» (Real Academia Española, ibíd.).

${ }^{34}$ Real Academia Española, Dictamen..., pág. 4.

35 Real Academia Española, ibíd. En la Advertencia de la edición de 1870 de la GRAE, la Academia, previendo las críticas a las que va a ser sometida, pone de relieve que sus miembros conocen perfectamente las doctrinas y métodos de las distintas corrientes de pensamiento lingüístico del momento. Por eso, se hace hincapié en que cuenta con «individuos muy familiarizados con la Gramática General, la Filología y la Lingüística» (Real Academia Española, Gramática..., 1870 , pág. XIII).

36 Diccionario de Autoridades (1726-1739), edición facsímil, Madrid, Gredos, 1963, s. v. gramática. 
que recoge una idea de gramática que comprende el examen de las 'letras', de la 'sílaba', de las 'partes de la oración' y de la 'construcción de las partes de la oración'» ${ }^{37}$.

F. A. Angulo, Secretario de la Real Academia Española, en su Proyecto de Gramática, declara que la división del arte «es uno de los mas peligrosos escollos de la Gramática, y como tal le han temido y huido muchos de los Gramáticos modernos» ${ }^{38}$. No obstante, siguiendo el juicio de A. Nebrija y G. Vosio, deja sentado que

una perfecta Gramática (como se pretende sea la española) debe constar de las quatro partes, que estos Autores la consideran, esto es, de Ortographia ${ }^{39}$, Prosodia, Etymologia, y Syntaxis, en que se comprehenden recta pronunciación, y escritura, partes de Oración, y Construcción, de que resulta la oración, cuyas quatro partes son tan necesarias, que faltando qualquiera de ellas, no puede aprenderse con perfección idioma alguno, que es el fin de las Gramáticas de todos ${ }^{40}$.

Más adelante reitera tal idea cuando enseña que las partes de la Gramática de nuestra lengua «deben ser las mismas, de que dexo fundado debe constar una perfecta Gramática, las quales hiran repartidas en tres partes, ô libros comprehendiendo el $1^{\circ}$ la Ortographia, y Prosodia: el $2^{\circ}$ la Etymologia: y el $3^{\circ}$ la Syntaxis, cuio fin es el mas natural y propio» ${ }^{41}$. En su disertación «Sobre si la gramatica ha de ser disertada o practica» ${ }^{42}$ (1742) insiste en que el texto gramatical ha de contener las cuatro partes que constituyen la disciplina, de acuerdo con la definición de arte de hablar y escribir correctamente ${ }^{43}$.

37 José Francisco Val Álvaro, Ideas gramaticales en el «Diccionario de Autoridades», Madrid, Arco/Libros, 1992, pág. 29.

38 Francisco Antonio Angulo, «Proyecto de Gramática», en Real Academia Española, Gramática de la Lengua Castellana, Madrid, Por D. Joachin de Ibarra, Impresor de Cámara de S. M., 1771. Edición facsímil y apéndice documental por Ramón Sarmiento, Madrid, Editora Nacional, 1984, [págs. 497-524], pág. 500.

39 F. A. Angulo considera la Ortografía parte fundamental de la Gramática, pues su objeto principal, enseñar a escribir correctamente, lo es también de la Gramática, ya que hablar y escribir son dependientes recíprocos:

las letras son signos de la pronunciación, por la qual fueron inventados los nombres, y figuras de ellas, y asi tienen una precisa relación, y correspondencia que las haze inseparables, y en confirmacion de esto Quintiliano dice, que el negocio de toda la Gramática consiste principalmente en dos cosas, hablar y escribir rectamente, y Gerardo Vosio que el nombre de la Gramática conbiene propiamente a la Ortographia, pero que por Synedoche se atribuye a todo el Arte (F. A. Angulo, ibíd.).

${ }^{40}$ F. A. Angulo, ibíd.

41 F. A. Angulo, Proyecto..., pág. 518.

42 Francisco Antonio Angulo, «Discurso sobre si la Gramatica ha de ser disertada o practica», en Real Academia Española, Documentos gramaticales.

${ }^{43}$ La Real Academia Española había publicado un tratado de Ortografía en 1741. En él se procura seguir un criterio intermedio entre el sostenido por los conservadores etimologistas y los 
En la edición de 1771 de la $G R A E$ se cambia de parecer en cuanto al número de partes que han de conformar la Gramática, al indicarse que se divide únicamente en dos, la que trata «del número, propiedad, y oficio de las palabras» ${ }^{44}$ y la que se ocupa «del órden y concierto que deben tener entre si, para expresar con claridad los pensamientos» ${ }^{45}$; en la de 1796 , como en el Diccionario de Autoridades y F. A. Angulo, se reconocen nuevamente cuatro, Analogía, Sintaxis, Prosodia y Ortografía; no obstante, el libro de Gramática lo constituyen solo las dos primeras, «omitiendo la Ortografía, porque anda en tratado separado, y la Prosodia, por no haber fixado todavía la Academia las reglas de la verdadera pronunciacion de las voces castellanas» ${ }^{46}$; en la de 1854 se vuelve a la división bipartita en Analogía y Sintaxis, y se explica que la Prosodia y la Ortografía son objeto de tratados especiales ${ }^{47}$; en la de 1858 , por primera vez en la $G R A E$, la definición de Gramática se extiende a la lengua escrita ${ }^{48}$. Por ello, se consideran como partes suyas la Analogía, la Sintaxis, la Prosodia y la Ortografía, aunque las dos últimas siguen siendo objeto de publicaciones independientes dada su «índole y extension» ${ }^{49}$.

En el Dictamen son reconocidas también estas cuatro disciplinas como constitutivas del arte de hablar y escribir correctamente, si bien se puntualiza que todas ellas han de formar parte del texto gramatical, perpetuando así la concepción que tenían los Académicos de la primera mitad del siglo XVIII. La Analogía y la Sintaxis, que resumen las reglas para hablar bien o correctamente un idioma, vienen impuestas por el buen método, que exige analizar primero y sintetizar a continuación; pero dicha corrección ha de extenderse a la «articulacion de las voces, á los accidentes del acento, de la cantidad y de la aspiracion de los sonidos ó signos orales que expresan las ideas» ${ }^{50}$, por lo que es inexcusable la Prosodia, «verdadera música gramatical indispensable» ${ }^{51}$, y a la

revolucionarios fonetistas (Emilio Cotarelo y Mori, Catálogo de las obras publicadas por la Real Academia Española, Madrid, Tipografía de la Revista de Archivos, 1928, pág. 10).

${ }^{44}$ Real Academia Española, Gramática..., 1771, pág. 1.

${ }^{45}$ Real Academia Española, Gramática..., 1771, págs. 1-2.

${ }^{46}$ Real Academia Española, Gramática de la Lengua Castellana, Quarta edicion corregida y aumentada, Madrid, Por la Viuda de Don Joaquin Ibarra, Impresora de la Real Academia, 1796, pág. 2.

${ }^{47}$ Real Academia Española, Gramática..., 1854, pág. 1, n. 1. En esta edición se explica que «los preceptistas suelen dividir la Gramática en cuatro partes, á saber, ortografía, analogía, sintáxis y prosodia» (Real Academia Española, ibíd.), proceder, como hemos visto anteriormente, seguido por la Real Academia Española en la edición de 1796 de la Gramática.

${ }^{48}$ En dicha edición es definida como el «arte de hablar con propiedad y escribir correctamente» (Real Academia Española, Gramática..., 1858, pág. 1). Esta definición es reproducida en los mismos términos hasta la de 1867 .

${ }^{49}$ Real Academia Española, Gramática..., 1858, pág. 1, n. 1.

${ }^{50}$ Real Academia Española, Dictamen..., pág. 3.

${ }^{51}$ Real Academia Española, Dictamen..., pág. 4. 
escritura, «complemento maravilloso del habla humana» ${ }^{52}$, de donde se deriva la necesidad de la Ortografía, puesto que el ser humano,

despues de haber pasado por los ensayos de la pintura y el símbolo, llegó á la escritura silábica, y por último á la alfabética: no satisfecho con expresar y analizar el pensamiento por medio de palabras, traduce las palabras, y analiza hasta sus últimos elementos, por medio de figuras, sujetando la fugacidad del signo acústico á la fijeza y duracion del signo óptico, gráfico é indeleble ${ }^{53}$.

Llegados a este punto, los miembros de la Comisión de Gramática declaran que no encuentran «valederas» ${ }^{54}$ las razones por las que la Prosodia y la Ortografía no se incluyen en la GRAE. Su índole hace aconsejable, por tanto, que formen parte del todo unitario, global y totalizador, que integran, con independencia de que sean tratadas con mayor detenimiento en textos autónomos; la extensión, otro de los motivos alegados desde antiguo para no incluirlas en la $G R A E$, según J. E. Hartzenbusch, A. Fernández-Guerra y Orbe y P. F. Monlau, tampoco supone un impedimento si se realiza una selección de los principios generales y de las normas más usuales, pues, de este modo, y con el debido uso de los recursos tipográficos, la nueva edición no alcanzará un volumen excesivo.

Esta propuesta es tenida en cuenta a la hora de redactar la edición de 1870. En ella se incluyen por primera vez en la GRAE la Prosodia y la Ortografía, lo que constituye un indicio inequívoco del normativismo de la citada edición, al extenderse la norma a la lengua escrita ${ }^{55}$.

En el apartado del Dictamen dedicado a la Ortografía se establece que en la Gramática han de ofrecerse los principios y fundamentos de la recta escritura de las palabras y las reglas necesarias para el uso adecuado de las letras y la puntuación. Sus firmantes manifiestan con rotundidad que la doctrina ortográfica de la Real Academia Española es la más acertada, y «verdaderamente digna de estar declarada oficial y exclusiva» ${ }^{56}$. No obstante, consideran razonable realizar ciertas modificaciones como anticipar el estudio de los nombres y de los orígenes de las letras con el fin de que la escritura española sea «la expresión más exacta de la pronunciación castellana, y refleje perfectamente los accidentes prosódicos, y, como ningun otro pueblo de la tierra, escriba lo mismo que habla» ${ }^{57}$. Asimismo, apuestan por un sistema de acentuación de las palabras lo más pedagógico posible: «sencillo, lógico, fácil de comprender á un golpe de vista y de retenerse constantemente en la memoria» ${ }^{58}$.

\footnotetext{
52 Real Academia Española, ibíd.

53 Real Academia Española, ibíd.

54 Real Academia Española, ibíd.

55 R. Sarmiento, art. cit., pág. 222.

56 Real Academia Española, Dictamen..., pág. 15.

57 Real Academia Española, ibíd.

58 Real Academia Española, ibíd.
} 
Como hiciera alrededor de cien años antes el entonces director, el duque de Alba, cuando aconseja la composición de una cartilla con la doctrina ortográfica de la Real Academia Española sintetizada para los que habían de iniciarse en la materia, por Real orden de 28 de abril de 1844 la Institución publica un Prontuario de Ortografía para su uso en las escuelas públicas. Antes de 1861 había conocido ocho ediciones, la última de 1859. En el Dictamen se propone que se siga en lo esencial el Prontuario, y que, partiendo de las recomendaciones anteriores, realizadas las modificaciones pertinentes, y debidamente aumentado con una tabla de las abreviaturas más frecuentes, se emplee para llenar el vacío de que adolece la Gramática en lo tocante a la Ortografía.

Por lo que respecta a la Prosodia, en el Dictamen se establece que en la Gramática ha de ofrecerse una noción clara sobre la disciplina y deben ser fijados los principios más incuestionables acerca del acento, la cantidad y la aspiración ${ }^{59}$. Poco más se comenta sobre esta parte de la Gramática, estudiada con detalle desde hacía años por la Comisión correspondiente. En la parte introductoria de la edición de 1870 de la GRAE se advierte que la Prosodia recogida en ella es la primera que publica la Real Academia Española, y que «en medio de lo mucho, y discorde, que sobre Prosodia se ha escrito, ha juzgado este Cuerpo literario que debía limitarse á consignar lo más esencial acerca de la Ortología alfabética (letras, sílabas, diptongos y triptongos), la acentuacion y la canti$d a d{ }^{60}$, a pesar de lo cual, siguiendo el criterio de perpetuo reformismo de la Corporación, se anuncia que «no renuncia, sin embargo, á nuevos estudios sobre esta materia difícil, é irá mejorando sucesivamente su obra» ${ }^{61}$.

5. Para los miembros de la Comisión de Gramática, una de las tareas más importantes que deben llevarse a cabo con vistas al perfeccionamiento y a la actualización de la GRAE es la reforma del capítulo dedicado al artículo. En el Dictamen y en numerosas Sesiones Académicas de los años 1861 y 1868, los miembros de la Corporación debaten aspectos esenciales de esta parte de la oración, como los fundamentos de su caracterización, y otros menores, como el orden en que es presentada dentro de la Gramática. Es significativo que, a pesar de ser la parte de la oración tratada de forma más breve en la GRAE, en el proyecto de reforma sea, junto con el verbo, a la que se le dedica mayor extensión. Desde la edición de 1796, atendiendo a una ordenación lógica, su estudio se antepone al del resto de las partes de la oración por el hecho de situarse generalmente delante del nombre. J. E. Hartzenbusch, A. Fernández-Guerra y Orbe y P. F. Monlau se oponen a esta distribución al considerar que, «siendo el artículo parte menos importante que el nombre, y una emanacion ó un acceso-

\footnotetext{
59 Real Academia Española, ibíd.

${ }^{60}$ Real Academia Española, Gramática..., 1870, pág. XV.

61 Real Academia Española, ibíd.
} 
rio de este, debe tratarse de él después, y no antes. La comprension es antes que la extension, lo principal antes que lo accesorio» ${ }^{62}$.

La Comisión de Gramática considera accidental, y, por ello, imprecisa, la concepción del artículo plasmada en la GRAE desde la edición de 1854 como determinante del género y el número de los sustantivos («parte de la oración, que sirve para determinar el género y el número de los nombres sustantivos» ${ }^{63}$ ), dado que

no es el artículo quien determina el género y el número de los sustantivos, sino estos los que determinan el número y el género de aquél. Tanto valdria decir que los adjetivos sirven para determinar el género y el número de los sustantivos, cuando es evidente que estos, como parte principal, son los que imponen la concordancia al adjetivo, lo mismo que al artículo ${ }^{64}$.

Siguiendo a los gramáticos filósofos franceses, la Comisión explica que la esencia del artículo, su función exclusiva, es «determinar la extension en que debe tomarse la idea expresada por los nombres apelativos» ${ }^{65}$. En la misma dirección se ubica cuando ofrece la siguiente explicación sobre los conceptos de comprensión y extensión:

La Comision ve con toda claridad, y profesa con los Gramáticos modernos, que toda idea general tiene su comprension fija ó constante, y su extension variable; la comprension la expresan los nombres genéricos ó apelativos, y la extension en que debe tomarse aquella comprension la marcan los artículos. Fuera de estos principios no caben mas que nociones falsas y reglas falibles ${ }^{66}$.

Sin embargo, la modernidad de estas doctrinas no cuaja de momento en la $G R A E^{67}$. Tras ser desestimada en la Sesión Académica del 22 de abril de 1861 la definición del artículo como determinante de la extensión del nombre sustantivo $^{68}$, en la edición de 1870 , siguiendo la línea más tradicional, es definido

62 Real Academia Española, Dictamen..., pág. 5.

63 Real Academia Española, Gramática..., 1854, págs. 3-4.

64 Real Academia Española, Dictamen..., pág. 5.

65 Real Academia Española, ibíd.

66 Real Academia Española, ibíd.

67 La definición del artículo basada en la función determinativa hubo de esperar hasta la edición de 1911 para ser incluida en la GRAE. En ella, bajo la influencia de E. Benot (1910), quien retoma la doctrina de lo consabido de A. Bello, es definido como «una parte de la oración que sirve principalmente para circunscribir la extensión en que ha de tomarse el nombre al cual se antepone, haciendo que éste, en vez de abarcar toda la clase de objetos a que es aplicable, exprese tan sólo aquel objeto determinado ya conocido del que habla y del que escucha» (Real Academia Española, Gramática de la Lengua Castellana, Nueva edición, Madrid, Perlado, Páez y Compañía [Sucesores de Hernando], Impresores y Libreros de la Real Academia Española, 1911, pág. 52).

68 Real Academia Española, Actas, 22 de abril de 1861. 
como una parte de la oración «que se antepone al nombre para anunciar su naturaleza y accidentes, y tambien á toda otra diccion, y áun á locuciones enteras, para indicar que ejercen en la oracion oficio de nombres» ${ }^{69}$.

En el Dictamen se replantean, asimismo, la adscripción categorial de un y la existencia de una o de dos clases de artículo, cuestiones directamente vinculadas. Se defiende la inclusión de la forma unos, y de pocos, muchos, algunos, ciertos, tantos, cuantos, tales, varios, en un grupo equivalente al de los denominados artículos demostrativos (articles démonstratifs) por A. I. Silvestre de Sacy. J. E. Hartzenbusch, A. Fernández-Guerra y P. F. Monlau niegan que sean adjetivos «porque nada adjiciunt, nada añaden á la comprension del nombre apelativo» ${ }^{70}$, ni pronombres, sino «verdaderos artículos que restringen la extensión total del nombre, bien que de una manera indeterminada, llamándose por esta razon artículos indefinidos» ${ }^{71}$. Habiendo sido rechazado en la Sesión del 6 de mayo de 1861 que un sea adjetivo determinativo ${ }^{72}$, y en la del día 13 aprobada en pleno la existencia de dos clases de artículo ${ }^{73}$, en la edición de 1870 de la GRAE se reconoce que un pertenece a esta parte de la oración.

6. En relación con el nombre, en el Dictamen solo se apuntan cuestiones menores, como que su organización en la Gramática carece del «orden conveniente» ${ }^{74}$, o que en el tratamiento del capítulo De las varias especies y diferencias de nombres se emite «tal cual idea que la Comision tiene por inexacta» ${ }^{75}$. Asimismo, se aboga por una mayor claridad en las cuestiones relativas al accidente de género, indicándose que «deberia formar un artículo mas bien que un capítulo, y presentarse bajo la forma de un cuadro sinóptico lo poco que con fijeza puede decirse sobre esta materia» ${ }^{76}$. Una de las novedades más importantes de la edición de 1870 de la GRAE, anunciada en la Advertencia ${ }^{77}$, la consideración como partes independientes de la oración del sustantivo y el adjetivo, incluidos con anterioridad en la categoría del nombre como clases suyas, curiosamente no es propuesta en el Dictamen de la Comisión de Gramática con vistas a su posible difusión en la nueva edición reformada del texto gramatical académico. Pese a ello, hay que apuntar que es fruto de la reflexión profunda de los miembros de la Corporación. Como toda reforma, se acomete tras ser sometida a la valoración y a la votación de los Académicos, no solo al juicio

\footnotetext{
69 Real Academia Española, Gramática..., 1870, pág. 9.

70 Real Academia Española, Dictamen..., pág. 5.

71 Real Academia Española, ibíd.

72 Real Academia Española, Actas, 6 de mayo de 1861.

73 Real Academia Española, Actas, 13 de mayo de 1861.

74 Real Academia Española, Dictamen..., pág. 6.

75 Real Academia Española, ibíd.

76 Real Academia Española, ibíd.

77 Real Academia Española, Gramática..., 1870, pág. XIV.
} 
de los miembros de la Comisión de Gramática o al de los integrantes de la Comisión encargada de la redacción de la GRAE. En las Sesiones Académicas de abril de 1861, cuando se inician las discusiones sobre los aspectos incluidos en el Dictamen que se pretenden modificar en la Gramática, se propone dicha innovación, aprobada en pleno en la Sesión del 23 de abril ${ }^{78}$.

7. Al ser abordado el análisis del tratamiento dado al pronombre en la $G R A E$, también se siguen las doctrinas de los gramáticos filósofos franceses. Se impugnan las definiciones de esta parte de la oración basadas en su naturaleza sustitutiva y, por tanto, las plasmadas en las ediciones anteriores a la elaboración del proyecto de reforma. Se afirma que el pronombre «no es una parte de la oracion que se pone en ella supliendo al nombre para evitar la repeticion de este» ${ }^{79}$, ni «aquella parte de la oracion que se pone en lugar del nombre, como dicen muchas Gramáticas» ${ }^{80}$, entre otras, la de la propia Real Academia Española en su edición princeps. En la línea de los ideólogos, se indica que los pronombres «son aquellas palabras ó partes de la oracion que expresan las personas que intervienen en el coloquio» ${ }^{81}$. Los únicos índices de persona gramatical son los personales, por lo que solo ellos pueden ser considerados como pronombres $^{82}$.

Ante tal situación, se plantea la necesidad de redistribuir los demostrativos, posesivos y relativos en otra parte de la oración. A juicio de la Comisión de Gramática, el papel de las formas incluidas en estas clases, y el de algunos numerales, sobre todo cardinales, es determinar la extensión del nombre sustantivo. Por ello, no son, como pretenden algunos autores, entre ellos V. Salvá, adjetivos, «pues nada añaden á la comprension de la idea expresada por el sustantivo» ${ }^{83}$, sino «verdaderos y legítimos artículos» ${ }^{84}$, puesto que «su funcion oracional única es determinar ó circunscibir la extension del nombre sustantivo» ${ }^{85}$.

Teniendo en cuenta la tendencia de los autores que, por temor a romper con la rutina de los preceptistas empíricos y «no pudiendo negarse á la evidencia» ${ }^{86}$ de que los demostrativos, posesivos y relativos son «verdaderos artículos» ${ }^{87}$, dividen los adjetivos en calificativos y determinativos, al poseer los elementos

78 Real Academia Española, Actas, 23 de abril de 1861.

79 Real Academia Española, Dictamen..., pág. 6. Esta definición del pronombre es la ofrecida en la GRAE desde la edición de 1796 hasta la de 1867.

80 Real Academia Española, ibíd.

81 Real Academia Española, ibíd.

${ }^{82}$ En el Dictamen se señala que «los llamados pronombres demostrativos, posesivos y relativos, no son tales pronombres» (Real Academia Española, ibíd.).

83 Real Academia Española, ibíd.

84 Real Academia Española, ibíd.

85 Real Academia Española, ibíd.

86 Real Academia Española, ibíd.

87 Real Academia Española, ibíd. 
incluidos en este grupo formas de adjetivo y determinar la extensión de los nombres sustantivos sin calificarlos, retomando las doctrinas de los gramáticos filósofos franceses insisten en que «no son ni pueden ser mas que artículos» ${ }^{88}$. En las disquisiciones sobre el pronombre que tienen lugar en las Sesiones Académicas de 1861 se advierte el compromiso con la tradición, al igual que en la edición de 1870 de la GRAE, en la que, en vez de ser definido de acuerdo con las directrices marcadas por los miembros de la Comisión de Gramática, es presentado como «una parte de la oracion que con frecuencia se pone en ella supliendo al nombre para evitar la repeticion de éste» ${ }^{89}$.

En cuanto a la adscripción categorial de los demostrativos, posesivos y relativos, en las Sesiones Académicas de 1861 se reconoce que son adjetivos, si bien, por respeto a la costumbre, se acuerda seguir estudiándolos en el capítulo dedicado al pronombre ${ }^{90}$. En la edición de $1870^{91}$ se mantiene este criterio, y se establece la división de los adjetivos en calificativos y determinativos, como se había hecho en la edición de 1869 del $D R A E^{92}$.

8. Los miembros de la Comisión de Gramática estiman que los capítulos dedicados al verbo en la GRAE adolecen de falta de orden y, «lo que es peor, de falta de exactitud» ${ }^{93}$ en algunos puntos. Consideran que están redactados «sin tomar bien en cuenta la índole esencialmente atributiva de esta parte de la oracion, ni hacerse cargo de la verdadera teoría de sus numerosos accidentes gramaticales» ${ }^{94}$. En su opinión, se ofrece «una idea imperfecta» ${ }^{95}$ del verbo ser, y se incide en «el error ${ }^{96}$, tantas veces combatido, de que en el verbo sustantivo se pueden resolver otros muchos por medio de un participio ó de un adjetivo verbal» ${ }^{97}$. Como se ve, rebaten la teoría del verbo único, que adquiere

88 Real Academia Española, ibíd.

89 Real Academia Española, Gramática..., 1870, pág. 41. La definición de la edición de 1870 de la GRAE es la reproducción literal de la ofrecida desde la de 1862.

90 Real Academia Española, Actas, 27 de mayo y 3 de junio de 1861.

91 Desde la edición de 1867, en la clasificación se enumeran además los indeterminados.

92 Real Academia Española, Diccionario de la Lengua Castellana, $11^{\mathrm{a}}$ ed., Madrid, Imprenta de Don Manuel Rivadeneyra, 1869, s. v. adjetivo.

93 Real Academia Española, Dictamen..., pág. 7.

94 Real Academia Española, ibíd.

95 Real Academia Española, ibíd.

96 Real Academia Española, ibíd. Este —según la interpretación de los miembros de la Comisión de Gramática- error es registrado en la GRAE desde la edición de 1796.

97 A propósito del ejemplo Tu hermano codicia honores y riquezas, propuesto en la GRAE, se matiza que difiere de Tu hermano es codicioso de honores y riquezas por el hecho de que ser codicioso denota «una cualidad, un carácter, un hábito» (Real Academia Española, ibíd.), y, codiciar, «un movimiento, una accion realizada de presente» (Real Academia Española, ibíd.); codiciar «supone reducida á acto la potencia, la cualidad ó el hábito de codicioso; hábito, cualidad ó potencia, que unas veces está en accion, y otras se mantiene latente» (Real Academia Española, ibíd.); el codicioso «no codicia á todas horas, y ratos del dia hay en que el hombre mas estudioso no estudia» (Real Academia Española, ibíd.). 
una amplia difusión a partir de su formulación en la Grammaire de PortRoyal ${ }^{98}$, según la cual, solo el verbo ser, existente en todas las lenguas, puede ser considerado como tal ${ }^{99}$.

La conjugación del verbo es caracterizada desde la edición de 1854 de la GRAE como «el conjunto de sus inflexiones y desinencias» ${ }^{100}$. Para la Comisión de Gramática, en esta definición se confunden las desinencias con las inflexiones, pues «la série de estas últimas es la que constituye la conjugacion, y nada tienen que ver con esta las desinencias» ${ }^{101}$

Por lo que respecta al tiempo, en opinión de los autores del Dictamen, no se da «idea alguna fundamental» ${ }^{102}$ de dicho accidente ${ }^{103}$; no se hace uso «de

${ }^{98}$ En ella se explica que

il n'y a que le verbe etre qu'on appelle substantif qui soit demeuré dans cette simplicité, \& encore l'on peut dire qu'il n'y est proprement demeuré que dans la troisiéme personne du present $e s t, \&$ en de certaines rencontres. Car comme les hommes se portent naturellemen à abreger leur expressions, ils ont joint presque tousiours à l'àffirmation d'autres significations dans vn mesme mot (Antoine Arnauld y Claude Lancelot, Grammaire générale et raisonnée, Stuttgart-Bad Cannstatt, F. F. Verlag, 1966, pág. 91),

añadiéndose a renglón seguido que

Ils y ont joint celle de quelque attribut: de sorte qu'alors deux mots sont vne proposition: comme quand je dis: Petrus vivit, Pierre vit: parce que le mot de vivit enferme seul l'affirmation, \& de plus l'attribut d'etre viuant; \& ainsi c'est la mesme chose de dire Pierre vit, que de dire, Pierre est vivant. De là est venuë la grande diuersité de verbes dans chaque Langue (A. Arnauld y C. Lancelot, ibíd.).

99 De acuerdo con la teoría del verbo único, el resto de los verbos contienen al verbo ser y, en última instancia, pueden ser reducidos a las combinaciones ser + adjetivo o ser + participio. Algunos autores que admiten estar como verbo sustantivo añaden también la combinación estar + gerundio (María Luisa Calero Vaquera, Historia de la gramática española (1847-1920), Madrid, Gredos, 1986, pág. 106).

${ }^{100}$ Real Academia Española, Gramática..., 1854, pág. 47.

101 Real Academia Española, Dictamen..., pág. 7. En la edición de 1870 no se producen cambios en este sentido. Así, se afirma que en el verbo «la serie ordenada de sus inflexiones y desinencias, lleva el nombre de conjugacion» (Real Academia Española, Gramática..., 1870, pág. 51).

102 Real Academia Española, Dictamen..., pág. 7.

${ }^{103}$ En la definición del verbo de la edición de 1796, el tiempo es citado entre sus accidentes gramaticales junto con los de modo, número y persona: «VERBO es una parte de la oracion que significa la exîstencia, accion ó pasion de las personas ó cosas, con varias terminaciones de modos, tiempos, números y personas» (Real Academia Española, Gramática..., 1796, pág. 87). Desde la edición de 1854 hasta la de 1867, el verbo es definido teniéndose en cuenta solamente sus rasgos semánticos, que ahora se ven incrementados con los de estado y designio, además del de esencia, citado ya en la de 1771: «Verbo es una parte de la oracion que significa la esencia, existencia, accion, estado, designio ó pasion de los seres vivientes y de las cosas inanimadas» (Real Academia Española, Gramática..., 1854, pág. 45). En la definición y caracterización del verbo de la edición de 1870 se citan menos rasgos semánticos (solo los de acción y estado) y vuelven a incluirse accidentes gramaticales (únicamente los de tiempo y persona): «parte de la oracion que designa accion ó estado, con expresion de tiempo y persona» (Real Academia Española, Gramá- 
la tan clásica y racional division de los tiempos en absolutos y relativos» ${ }^{104}$, ni «en rigor se explica el mecanismo de su formacion» ${ }^{105}$.

En efecto, el accidente gramatical de tiempo no es caracterizado adecuadamente en ninguna edición de la GRAE anterior al Dictamen. Simplemente, se ofrece la enumeración de los tiempos de los diferentes modos del verbo, con las correspondientes subdivisiones, y alguna explicación, normalmente de carácter semántico, acerca de algunos de ellos, así como del uso de los que, dependiendo de las ediciones, se considera pertinente matizar.

En la edición de 1870 se emplea por primera vez en la GRAE la demandada por la Comisión de Gramática división de los tiempos del verbo en absolutos y relativos, al puntualizarse que los tiempos considerados en la Gramática, pasado, presente y futuro, coincidentes con los que existen en la realidad, son absolutos, mientras que aquellos otros en los que se subdividen son intermedios o relativos.

El mecanismo de la formación de los verbos no es explicado en las ediciones de la GRAE anteriores a la composición del Dictamen y continúa sin hacerse en las siguientes.

Acerca del gerundio, forma verbal considerada desde la edición de 1854 de la GRAE voz del infinitivo ${ }^{106}$, se le objeta al texto gramatical académico no «haber dicho que el infinitivo tiene voces, ni en qué consisten estas» ${ }^{107}$.

tica..., 1870, pág. 50). Desde la de 1874, con independencia de las definiciones, que varían dependiendo de la edición, se puntualiza que el verbo designa «casi siempre» (Real Academia Española, Gramática..., 1874, pág. 72) «expresión de tiempo y persona» (Real Academia Española, ibíd).

104 Real Academia Española, Dictamen..., pág. 7. G. Correas, con el precedente de A. Nebrija, percibe la separación entre tiempos absolutos y relativos (Antonio Ramajo Caño, Las gramáticas de la lengua castellana desde Nebrija a Correas, Ediciones Universidad de Salamanca, 1987, pág. 164). La división de los tiempos en absolutos y relativos, situándose los sucesos no solo con relación al presente (absolutos [pretérito, presente y futuro]) sino también con otro suceso fechado (pretérito anterior, pretérito simultáneo, etc.), es la máxima innovación de la Grammaire de Port-Royal, que se mantiene con gran vitalidad en Francia y es adoptada por los gramáticos más representativos del racionalismo francés. Sin embargo, en las gramáticas españolas anteriores a la de A. Bello es casi desconocida.

105 Real Academia Española, Dictamen..., pág. 7.

106 En la edición de 1854 de la GRAE, el infinitivo, modo al que se considera que pertenecen el gerundio y los participios activo y pasivo, se divide en simple, o presente (amar), y pretérito (haber amado), con significación este último análoga a la del pretérito compuesto de indicativo. En la edición de 1870, en la que la caracterización del infinitivo se completa con la adición de nuevos datos de interés sobre su estructura, también se ofrecen las terminaciones del gerundio y los participios activo y pasivo, pertenecientes, como hemos indicado anteriormente, al modo infinitivo. En la de 1917, el infinitivo, el único tratado en la Analogía, bajo el epígrafe de modos (ya que los restantes se encuentran bajo el de tiempos o en la Sintaxis), se establece que comprende los llamados nombres verbales, que son el infinitivo propiamente dicho, «que expresa la idea del verbo como puede hacerlo un nombre de acción» (Real Academia Española, Gramática de la Lengua Castellana, Nueva edición, reformada, Madrid, Perlado, Páez y Compañía [Suceso- 
Si en el proyecto de Gramática se explica que la declinación de los nombres en las primeras épocas de formación de las lenguas fue el resultado de la aposición del artículo al radical del nombre, sobre la formación de los verbos en las conjugaciones griega y latina y su ulterior desarrollo, haciendo hincapié en la formación de los tiempos, en los de las lenguas neolatinas se aduce la siguiente explicación en la misma línea historicista:

las conjugaciones griega y latina fueron el resultado de la aposicion del verbo de movimiento eo, ire, al radical de los demás verbos, así como la conjugacion de este no fué mas que el resultado de la aposicion del pronombre á su radical [...]. En las lenguas neo-latinas la conjugacion es un puro reflejo de la conjugacion latina, y sus tiempos se forman, ó romanceando simplemente los latinos, ó añadiendo al radical del verbo los tiempos de un verbo auxiliar. Esto es, pues, lo que debiera decir nuestra GRAMÁTICA al tratar de la formacion de los tiempos; y á la luz de tales explicaciones veríase con toda claridad que and-uve, and-uviera, etc., no son efectivamente, ni pueden ser, mas que and-hube, and-hubiera, que es decir, el radical and, de andar, con el auxiliar haber. Lo propio sucede en el verbo Estar._¿Hay nada mas patente que la ingeniosa composicion del futuro absoluto en todas las lenguas romances? El futuro castellano, por ejemplo, no es mas que el infinitivo del verbo unido al presente del auxiliar haber: véase si se encontrará otra cosa en amar-he, amar-has, amar-ha, amar-hemos ó habemos, amar-heis ó habeis, y amar-han. Lo propio acontece en todos los verbos, incluso el sustantivo Ser, $\mathrm{y}$ en todas las lenguas de la Europa occidental ${ }^{108}$.

A partir de esta explicación, nada nueva entre los gramáticos y lingüistas de la época, la Comisión de Gramática indica que la formación de los tiempos se podría explicar con claridad y «expeditísima aplicacion» ${ }^{109}$, y deduce que en su

res de Hernando], Impresores y Libreros de la Real Academia Española, 1917, pág. 40); el participio, «que la denota como un adjetivo» (Real Academia Española, ibíd.), y el gerundio, «como un adverbio» (Real Academia Española, ibíd.).

107 Real Academia Española, Dictamen..., pág. 7. Otros aspectos criticados en el Dictamen a propósito de los capítulos dedicados al verbo en la Gramática son: 1) El estudio del verbo haber y de su conjugación como activo al inicio del tratamiento de los verbos auxiliares, anticipándose al de los irregulares de la segunda conjugación, lugar en el que, a juicio de la Comisión, tendría que estar. Ello es debido, según el parecer de los autores del Dictamen, al desconocimiento en la formación de los tiempos del verbo. 2) La falta de información sobre la formación de los verbos regulares, acerca de la cual solamente se ofrece la conjugación de los verbos amar, temer y partir, y no se separa la parte radical de la que presenta la inflexión. 3) En el tratamiento de los verbos irregulares se echa de menos una separación entre los que la presentan en las flexiones y los que «solo ofrecen tal cual permutacion ó adicion eufónica» (Real Academia Española, ibíd.) en la parte radical, así como, en el artículo de la formación de los tiempos compuestos, alguna indicación sobre las inflexiones de los tiempos del pretérito perfecto de indicativo y del pretérito imperfecto y futuro imperfecto de subjuntivo.

108 Real Academia Española, Dictamen..., pág. 8.

109 Real Academia Española, ibíd. 
formación las irregularidades aparecen como «simples exigencias naturales de la eufonía ó de la pronunciacion» ${ }^{110}$.

9. El participio, que en la GRAE recibe la consideración de parte independiente de la oración hasta la edición de 1916, en el Dictamen es denominado «modo impersonal» ${ }^{111} \mathrm{o}$ «parte de la oracion» ${ }^{112}$. En él se pone de relieve que se caracteriza por el hecho de participar de la naturaleza léxico-gramatical del adjetivo y del verbo al igualar «sus accidentes gramaticales con los del sustantivo á quien se refiere» ${ }^{113}$ y tomar «los accidentes del tiempo y de la voz y el mismo régimen que el verbo» ${ }^{114}$. A renglón seguido se puntualiza que «esto mismo quiere decir la GRAMÁTICA que examinamos, pero no lo dice todo, ni con la debida claridad» ${ }^{115}$.

Frente la crítica realizada en la edición de 1858 de la $G R A E$ en relación con la división de los participios en activos y pasivos, o en presentes y pretéritos ${ }^{116}$, en el proyecto de reforma se alega que «semejante distincion nos parece, sobre innecesaria, poco exacta, porque en ambos se prescinde del tiempo, el cual lo determinan en cada caso los verbos de que se acompañan» ${ }^{117}$, y se señala que, además de tratarse de una «cuestion de la cual podia haber prescindido» ${ }^{118}$, carece de fundamento, ya que

110 Real Academia Española, ibíd. Acerca del capítulo X, dedicado a los verbos impersonales, defectivos, compuestos y frecuentativos, se advierte que la forma impersonal de los primeros constituye más bien «un modo del verbo que una clase de verbos» (Real Academia Española, Dictamen..., 1861, pág. 9); que el artículo de los verbos compuestos «está fuera de su lugar» (Real Academia Española, ibíd.), pues sería suficiente con dar una idea general en los preliminares; y que el tratamiento de los verbos frecuentativos, incoativos y «demás que modifican la acepcion del primitivo en virtud del procedimiento gramatical de la derivacion, que es decir en virtud de desinencias especiales que los romances tomaron ó han imitado del latin» (Real Academia Española, ibíd.), resulta escaso.

111 Real Academia Española, ibíd. Ha de tenerse en cuenta que en las gramáticas españolas posteriores a 1917 compuestas sobre el modelo de las latinas el participio solía ser interpretado como un modo. Por ejemplo, en la de Luis Penagos se mencionan como tales el indicativo, subjuntivo, potencial, imperativo, infinitivo, gerundio y participio, anotándose de este último que «expresa solamente la acción o un hecho y equivale a veces a un adjetivo» (Luis Penagos, Gramática de la Lengua Española, 2a ed., Santander, «Sal Terrae», 1961, pág. 28).

112 Real Academia Española, Dictamen..., pág. 9.

113 Real Academia Española, ibíd.

114 Real Academia Española, ibíd.

115 Real Academia Española, ibíd. En la edición de 1858 de la GRAE se afirma que «el participio es una parte de la oracion llamada así porque participa de nombre y verbo. Participa de nombre en cuanto por lo comun tiene todas las propiedades de adjetivo, y de verbo en cuanto significa accion ó pasion como él» (Real Academia Española, Gramática..., 1858, págs. 106-107).

116 A propósito de la división de los participios en activos y pasivos, en la edición de 1870 de la GRAE se subraya, de acuerdo con la indicación del Dictamen, que también suelen denominarse «de presente y de pretérito» (Real Academia Española, Gramática..., 1870, pág. 127).

117 Real Academia Española, Gramática..., 1858, pág. 107.

118 Real Academia Española, Dictamen..., pág. 9. Esta cuestión es tenida en cuenta en la elaboración de la edición de 1870 de la GRAE, pues en ella tales consideraciones son eliminadas. 
todo participio es igual al relativo y al verbo de donde nace puesto en presente, en pretérito ó en futuro: semejante es igual á el que se semeja (presente) - juntado es igual á el que ha sido objeto pasivo de la accion de juntar (pretérito)—, y los pocos participios, ó nombres en forma de tales, que tenemos en uro, y ando, endo, envuelven necesariamente la idea de tiempo futuro. ${ }^{119}$

Ante la afirmación de la edición de 1858 de la GRAE de que los participios pasivos de la segunda y tercera conjugación acaban en ido, al observarse que no se comenta que en español antiguo algunos de ellos lo hicieron en udo y que en la página 69 se había dado cuenta del uso antiguo de algunos tiempos, se recalca que

tambien pudiera haberse dicho aquí que muchos participios en ido fueron antiguamente en $u d o$ : nada, realmente, mas comun en los documentos antiguos, y en los primeros monumentos en verso y prosa de nuestro romance, que los participios pasivos connozudo, corrompudo, encendudo, percebudo, prendudo, sabudo, tenudo, venzudo, etc. ${ }^{120}$

Sobre los participios llamados irregulares, se ve la conveniencia de hacer notar que todos son pasivos, ya que «los activos en ante y ente llevan en esta desinencia, reflejo del ontos griego, ó del ens, entis, ó del iens, euntis, latino, una invariabilidad como esencial, y dependiente del concepto necesario de la existencia presente que significan» ${ }^{121}$. Por otro lado, a propósito de la irregularidad de gran parte de los participios pasivos, se puntualiza que solo es aparente, dado que

los llamados contractos, sobre todo, cuyo uso tanto se ha generalizado desde principios del siglo XVII, lejos de ser irregulares, están romanceados con perfecta regularidad y analogía, pues se tomaron directamente del latin, y del latin correcto; y se tomaron para el servicio puramente adjetivo, mas bien que para el uso participial ${ }^{122}$.

119 Real Academia Española, ibíd. Para corroborar esta idea, se cita la definición de participio de Nebrija: «Participio (dice Lebrija) es una de las diez partes de la oracion que significa hazer é padecer EN TIEMPO»(Real Academia Española, ibíd.). Como puede comprobarse, teniéndose en cuenta el modelo de la gramática latina, también se incluyen las formas correspondientes a los participios de presente - activo- (semejante), de pretérito — pasivo- (juntado), y de futuro - activo- (uro), —y pasivo- (ando, endo). A propósito de estas se nos ofrece la siguiente explicación:

Nada dice nuestra GRAMÁTICA de los participios de futuro, y eso que la misma palabra futuro, y las de pasaturo, venturo, etc., están revelando que algo del futuro en rus latino ha quedado en el romance castellano.-Tampoco fuera inoportuno llamar la atencion acerca de los nombres dividendo, examinando, minuendo, nefando, sustraendo, vitando, etc., vivas reminiscencias del participio de futuro en $d u s$, cuyo valor y fuerza conservan, aún en medio de no usarse mas que como puros sustantivos ó adjetivos (Real Academia Española, Dictamen..., pág. 10).

${ }^{120}$ Real Academia Española, Dictamen..., págs. 9-10.

121 Real Academia Española, Dictamen..., pág. 10.

122 Real Academia Española, ibíd. 
Por lo demás, se considera importante excluir de las páginas dedicadas al participio en este capítulo de la Analogía las cuestiones relativas al régimen de los participios activos ${ }^{123}$ («Todo lo que se dice en seguida acerca del régimen del participio corresponde á la Sintáxis, y por lo tanto debe eliminarse de la Analogía» ${ }^{124}$ ) y a los oficios del participio pasivo ${ }^{125}$ : «Daremos fin á las observaciones sobre el participio, añadiendo que casi todo lo que en la página 112 se dice acerca de los oficios del participio pasivo ha de pasar á la Sintaxis» ${ }^{126}$.

10. El adverbio, en opinión de J. E. Hartzenbusch, A. Fernández-Guerra y Orbe y P. F. Monlau, está tratado con claridad y exactitud en la GRAE. En la edición de 1854 se enseña, como tantos autores desde Prisciano, que «el adverbio es con relacion al verbo lo que el adjetivo respecto del sustantivo» ${ }^{127}$, con lo que se pone de relieve el análogo funcionamiento sintáctico de las clases sustantiva y adjetiva ${ }^{128}$. Manifiestan su conformidad con tal comparación porque «es muy propia para dar una idea adecuada del adverbio» ${ }^{129}$. No obstante, echan en falta que no se explique «que todo adverbio fué primitivamente un nombre ${ }^{130}$, y que por eso todo adverbio equivale á una preposicion mas un

123 Lo expuesto en las páginas 107 y 108 de la edición de 1858 de la GRAE acerca del régimen de los participios activos se resume en estas palabras que constituyen el punto de partida de la cuestión: «No de todos los verbos se pueden formar participios activos usuales, ni todos los que pueden formarse se deben considerar como tales, por no conservar el régimen de sus verbos» (Real Academia Española, Gramática..., 1858, pág. 107).

124 Real Academia Española, Dictamen..., pág. 9.

125 Los oficios asignados al participio pasivo en la edición de 1858 de la GRAE son los de «juntarse con el verbo auxiliar haber» (Real Academia Española, Gramática..., 1858, pág. 112) para la formación de los tiempos compuestos (he sido; has estado; habrás determinado), «juntarse con el verbo auxiliar ser, para suplir la voz pasiva de los verbos» (Real Academia Española, Gramática..., 1858, pág. 113) (El dinero es buscado; Las riquezas son apetecidas; El mérito es aborrecido por la envidia), «juntarse con sustantivos, y concertar con ellos en género y número como adjetivo» (Real Academia Española, ibíd) (hombre perdido; obra acabada; haciendas adquiridas), o «usarse como absoluto»(Real Academia Española, ibíd.): Tomado el gusto al estudio, no hay cosa que más deleite; Sosegados los alborotos, se restableció la abundancia; Aprendida la Gramática, abre caminos para muchos conocimientos.

126 Real Academia Española, Dictamen..., pág. 10.

127 Real Academia Española, Gramática..., 1854, pág. 110. No obstante, se puntualiza que se diferencian, «no solo en que aquél no tiene singular y plural como todos los adjetivos, ni dos terminaciones como muchos, sino tambien en que el adverbio modifica de distinto modo el sentido de la oracion, porque expresa una circunstancia, al paso que el adjetivo da una calificacion» (Real Academia Española, ibíd.).

$128 M^{a}$ L. Calero Vaquera, op. cit., págs. 142-143.

129 Real Academia Española, Dictamen..., pág. 10.

$130 \mathrm{El}$ adverbio aparece tratado por primera vez como categoría independiente en la tercera clasificación de las partes de la oración efectuada por los estoicos al ser separado del nombre común $(\pi \rho \circ \sigma \eta \gamma o p i \alpha)$, debido, tal vez, a que se advirtiera, como el mismo nombre que le aplicaron ( $\mu \varepsilon \sigma o ́ \tau \eta \varsigma)$ hace suponer, que ocupaba una posición intermedia entre el verbo, del que depende sintácticamente, y el nombre común, al que se encuentra más vinculado desde el punto de vista morfológico. 
nombre» ${ }^{131}$, teoría que parte Port-Royal y que fue seguida por C. Ch. du Marsais, N. Beauzée, E. B. de Condillac, A. L. Destutt de Tracy o A. I. Silvestre de Sacy, entre otros autores.

11. J. E. Hartzenbusch, A. Fernández-Guerra y Orbe y P. F. Monlau consideran conveniente llevar a cabo una «reforma capital» ${ }^{132}$ en el capítulo de la $G R A E$ dedicado a la preposición, ya que desde la edición de 1854 se venía explicando que esta parte de la oración se antepone a otras para denotar la relación de estas «con el sujeto principal de la cláusula» ${ }^{133}$.

Los autores del Dictamen matizan que, si bien es cierto que la preposición indica dicha relación, esta se da entre el antecedente y el consecuente o complemento, con independencia de que sean o no partes principales de la oración. Así, en Juan escribe con plumas de acero, con indica una relación entre escribir (antecedente) y plumas (consecuente), y de, la existente entre plumas y acero, donde se comprueba que ninguna de las palabras unidas por la preposición es el sujeto de la oración.

Por el contrario, subrayan que las partes principales de la oración, «el nominativo y el verbo» ${ }^{134}$, se relacionan sin ser necesario para ello el empleo de la preposición, sino, simplemente, mediante su consecución en la cadena hablada, como se comprueba en el ejemplo Juan escribe comedias, en el que la relación entre Juan y escribe, y escribe y comedias, «se hallan intencionalmente expresadas por la enunciacion simple é inmediata de las tres palabras» ${ }^{135}$.

A propósito del paralelismo establecido en el apartado dedicado a la reforma del adverbio entre esta parte de la oración y la combinación de preposición + nombre, comentan que en el orden cronológico de las partes de la oración la preposición debió de ser anterior al adverbio, por lo que se propone darle prioridad en el estudio en la Gramática. Sin embargo, esta propuesta no prospera en la edición de 1870 de la GRAE.

12. Al acometerse en el Dictamen el análisis de la conjunción, en consonancia con las doctrinas de los ideólogos, se pone de relieve que, por su condición de elemento de enlace entre oraciones y por no pertenecer a ninguna de ellas, es parte del discurso, no de la oración ${ }^{136}$ como se defiende en la GRAE, y que, incluso en aquellos casos en los que en apariencia une solo palabras, en-

131 Real Academia Española, Dictamen..., pág. 10.

${ }^{132}$ Real Academia Española, ibíd.

${ }^{133}$ Real Academia Española, Gramática..., 1854, pág. 119.

134 Real Academia Española, Dictamen..., pág. 10.

135 Real Academia Española, Dictamen..., págs. 10-11.

${ }^{136}$ En este sentido, en el Dictamen se lee que «las Conjunciones, mas bien que partes de la oracion, son partes del discurso: sirven para enlazar dos oraciones, pero en rigor no pertenecen á ninguna de ellas; son, en una palabra, el exponente de la relacion que hay entre dos oraciones» (Real Academia Española, Dictamen..., pág. 11). 
laza oraciones siempre, ya que «si aparentemente se encuentran á veces enlazando palabras dentro de una oracion única, es porque se comete una elipsis muy natural en aquellas oraciones que tienen ciertos elementos comunes» ${ }^{137}$. Desde la edición de 1771 de la GRAE, la conjunción había sido concebida como una parte de la oración que une palabras u oraciones ${ }^{138}$. Dicho juicio, para los miembros de la Comisión de Gramática, es tan repetido como inexacto, pues «en rigor las conjunciones no enlazan mas que oraciones» ${ }^{139}$. En la edición de 1870, como en el proyecto de reforma, se explica que la conjunción «es aquella palabra ó frase que sirve para denotar la relacion que hay entre dos oraciones ó entre dos proposiciones de una misma oracion» ${ }^{140}$, a lo que, casi en los mismos términos que en el Dictamen, se añade que «supone pluralidad de oraciones, aunque muchas veces se encuentre juntando palabras dentro de una oracion al parecer única» ${ }^{141}$, por lo que implica «una elipsis ó supresion; supresion muy natural en aquellas oraciones que tienen ciertos elementos comunes. Estos elementos se enuncian una sola vez, y las palabras diferentes aparecen entónces enlazadas por conjunciones» ${ }^{142}$.

Por lo que respecta a la forma que ${ }^{143}$, la Comisión de Gramática piensa que equivale a la combinación de conjunción copulativa + artículo demostrativo

137 Real Academia Española, ibíd.

138 En la edición de 1771 de la GRAE se indica que la conjunción «sirve para juntar, atar, ó trabar entre sí las demas partes de la oracion» (Real Academia Española, Gramática..., 1771, pág. 222). Desde la de 1796 se subraya que une palabras y oraciones: «CONJUNCION es una parte de la oracion, que sirve para enlazar las palabras y las oraciones unas con otras» (Real Academia Española, Gramática..., 1796, pág. 263).

139 Real Academia Española, Dictamen..., pág. 11.

140 Real Academia Española, Gramática..., 1870, pág. 155.

141 Real Academia Española, ibíd.

142 Real Academia Española, ibíd.

143 Para la Comisión de Gramática, hubiera sido innecesaria la advertencia que se ofrece en la $G R A E$ de que no se debe confundir el que conjunción con el que pronombre relativo si

\begin{abstract}
se hubiese dado una verdadera idea de esta parte de la oracion. El que indeclinable de los romances no significa otra cosa que el declinable latino quis, quae, quod, quid, del cual se formó; y quis, quae, quod, quid [...], no es otra cosa que la contraccion de is, $e a, i d$, con la conjuncion que, procedente de la raiz griega te, ke. Así, quis vale literalmente et is, quid vale et id, quod es lo mismo que et hoc. Lo mismo en el castellano y demás romances: que vale tanto como y este, y esta, y esto; es decir que equivale á una conjuncion copulativa mas un artículo demostrativo (Real Academia Española, Dictamen..., págs. 11-12).
\end{abstract}

N. Beauzée había explicado que «cette propriété conjonctive est telle, que l'on peut toujours décomposer qui, quae, quod par is, ea, id, \& par une conjonction telle que peuvent l'exiger les circonstances du discours» (Nicolas Beauzée, Grammaire générale, ou exposition raisonnée des éléments nécessaires du langage, pour servir de fondement à l'étude de toutes les langues. Nouvelle impression facsimilé de l'édition de 1768 avec une introduction par B. E. Bartlett, StuttgartBad Cannstatt, F. Frommann Verlag [Holzboog], 1974, pág. 366). 
(«conjuncion incorporada con un artículo demostrativo» ${ }^{144}$ ) y, en consecuencia, considera que es un «artículo conjuntivo» ${ }^{145}$, según habían apuntado ciertos gramáticos franceses, como N. Beauzée ${ }^{146}$, dado que «esto es, efectivamente, y no otra cosa; y cuantos gramáticos desconocen esta su índole inalterable, se encuentran á cada paso atascados, y constreñidos á hacer distinciones, excepciones y advertencias infundadas» ${ }^{147}$.

13. Las interjecciones, signos sin un lugar concreto en la oración, «emisiones casi espontáneas de la voz» ${ }^{148}$, a diferencia de las oraciones, reflejo de nuestros pensamientos, «traducen mas bien las emociones de la sensibilidad que los actos de la inteligencia» ${ }^{149}$. En el Dictamen, de acuerdo con la caracterización logicista de oración como expresión de un juicio propuesta en él, se contraviene la doctrina incluida en la $G R A E^{150}$, al hacerse hincapié en que las interjecciones no son partes de la oración, sino partes del discurso que equivalen a oraciones enteras: «una interjeccion es una oracion completa, es la expresion del estado afectivo del que la emite; pero de esa oracion sintética, minuciosamente analizada, surge todo un desarrollo lingüistico» ${ }^{151}$, donde se advierte el eco de la Gramática General, presente, como se ha visto, en la génesis filosófica del Dictamen. En este sentido, al hacerse referencia a lo poco que, dada su invariabilidad, puede explicarse acerca de las interjecciones en la primera parte de la Gramática, se subraya que

Apenas tienen estructura gramatical, y es muy poco lo que acerca de ellas hay que exponer en la Analogía. Este poco, sin embargo, conviene decirlo de una manera que guarde consonancia con el punto de vista lógico bajo del cual debe redactarse toda Gramática ${ }^{152}$.

144 Real Academia Española, Dictamen..., pág. 12.

145 Real Academia Española, ibíd.

146 Este autor rechaza el término relativo (relatif) y considera más exacta la denominación de artículo demostrativo conjuntivo (article démonstratif-conjonctif) (N. Beauzée, op. cit., 1974, pág. 366).

147 Real Academia Española, Dictamen..., pág. 12.

148 Real Academia Española, ibíd. Por este motivo, B. Jiménez Patón, bajo la influencia del Brocense, niega a la interjección el carácter de parte de la oración al considerar que no pertenece al lenguaje humano, ya que los animales también usan determinadas voces que se asemejan a nuestras interjecciones: «La interjeción en latín, griego o español, no hace parte de oración, porque las partes de la oración an de sinificar por aluedrío de los hombres, y no naturalmente. La interjeción es un afecto del ánimo que sinifica sus pasiones naturalmente, luego no puede constituir parte de la oración» (Epítome de la ortografía latina y castellana. Instituciones de la gramática española. Estudio y edición de A. Quilis y J. M. Rozas, Madrid, CSIC, 1965, pág. 104).

149 Real Academia Española, Dictamen..., pág. 12.

150 Desde la edición de 1771 hasta la de 1852, la interjección es denominada simplemente palabra, y también parte de la oración. Desde la de 1854 se emplea, asimismo, el término voz.

151 Real Academia Española, Dictamen..., pág. 12.

152 Real Academia Española, ibíd. 
Las consideraciones precedentes perpetúan la línea emprendida por algunos ideólogos como A. L. Destutt de Tracy, quien niega el carácter de parte de la oración de las interjecciones, destaca que forman una proposición entera («ces mots forment une proposition toute entière» ${ }^{53}$ ) y pone de relieve su condición de

véritables phrases elliptiques. Aussi, est-ce dans les momens ou la force de la pasión nous presse de manifester nos sentiments, et nous laisse peu de liberté d'esprit pour les analyser, que nous nous servons plus volontiers et plus fréquemment des locutions de ce genre ${ }^{154}$.

En la edición de 1870 de la GRAE, igual que en las anteriores, las interjecciones son enumeradas entre las partes de la oración, y concebidas como tales, aunque en aquella se pone de relieve su equivalencia con las oraciones: «las interjecciones, más bien que partes de la oracion, son oraciones enteras» ${ }^{155}$.

14. Al abordar el análisis del tratamiento dado a la Sintaxis en la GRAE, los miembros de la Comisión de Gramática parten de la consideración de que, del mismo modo que para que se constituya un pensamiento no es suficiente la coexistencia de ideas en la conciencia sin una razón que imponga cierto orden entre ellas, no es posible enunciarlo con la mera acumulación de partes de la oración si no están relacionadas de acuerdo con ciertos principios reguladores bajo un orden lógico determinado. Así, pues, si la Etimología es «la razon de las palabras» ${ }^{156}$, la Sintaxis es «la razon de las oraciones» ${ }^{157}$.

J. E. Hartzenbusch, A. Fernández-Guerra y Orbe y P. F. Monlau señalan que los principios «verdaderamente filosóficos» ${ }^{158}$ de la Sintaxis, «muy pocos

153 Antoine Louis Destutt de Tracy, Éléments d'idéologie, II, $2^{\mathrm{e}}$ éd., Paris, $\mathrm{M}^{\mathrm{me}} \mathrm{V}^{\mathrm{e}}$ Courcier, 1817, pág. 69.

154 A. L. Destutt de Tracy, op. cit., pág. 70. Este autor considera que la interjección es la parte más importante del discurso, el modelo original de lenguaje del que se han formado las restantes: «c'est-là vraiment le type originiel du langage. Toutes les autres parties du discours ne sont que des fragmens de celles-là, et ne sont destinées qu'a la décomposer, et à la résoudre dans ses élémens»(A. L. Destutt de Tracy, ibíd.). En España conciben la interjección en esta línea González de Valdés, Calleja, Gómez Hermosilla, Alemany, Noboa, Mata, Calderón y Amézaga.

155 Real Academia Española, Gramática..., 1870, pág. 163. Desde la edición de 1911 de la GRAE se aclara que «la interjección es una parte de la oración que generalmente forma por sí sola una oración completa» (Real Academia Española, Gramática..., 1911, pág. 209).

156 Real Academia Española, Dictamen..., pág. 13.

157 Real Academia Española, ibíd. Desde la edición de 1796 de la GRAE, la Sintaxis se divide en regular (o natural en esta edición) y figurada. En la Sintaxis regular se estudian las reglas de la concordancia, el régimen y la construcción en los capítulos correspondientes. Esta división de la Sintaxis obedece a la conveniencia de estudiar en apartados distintos los hechos gramaticales que se corresponden con el orden de los pensamientos y los que no observan tal correspondencia. Desde el momento en que la Sintaxis se concibe desde el punto de vista de la lógica «es preciso constituir una sección independiente con los hechos de la lengua que no se atienen a ella: la sintaxis figurada» ( $\mathrm{M}^{\mathrm{a}}$ L. Calero Vaquera, op. cit., pág. 198).

158 Real Academia Española, Dictamen..., pág. 13. 
en número, por lo mismo que son universalísimos» ${ }^{159}$, se reducen a la concordancia, el régimen y la construcción. Conscientes de que cada idioma a lo largo del tiempo ha configurado su Sintaxis del modo que le ha parecido más adecuado, imitando la de otras lenguas, tomando giros propios y especiales o ateniéndose al uso, explican que «la sintáxis de una lengua no viene á ser mas que la consignacion de hechos, de lo que se usa, de lo que existe, sea cual fuere la razon de su existencia; y por lo tanto no hay que pedir á sus reglas filosofía, sino verdad, exactitud, conformidad con los hechos» ${ }^{160}$. Tales consideraciones confirman que el empirismo, presente anteriormente en la doctrina gramatical académica aunque en segundo plano, bajo la influencia de la Filología Comparada pasa a inspirar como «principio rector la doctrina de $1870 »{ }^{161}$.

La Real Academia Española acomete la reforma de la Gramática con el propósito de acoger aquellos asertos e inducciones de la nueva lingüística que lleven impreso «el sello y carácter de certeza definitiva» ${ }^{162}$. Por ello, en el Prólogo de la edición de 1870 se puntualiza que la Institución «no puede dejarse llevar de teorías generales, sino que ha de atenerse á los hechos, á lo que real y prácticamente es, prescindiendo de lo que filosóficamente debiera ó pudiera ser» ${ }^{163}$; asimismo, se indica que

no puede ni debe guiarse por el prurito de filosofar [...], sino que ha de limitarse á consignar el estado real y presente del idioma, á registrar las leyes instintivas á que obedece en su curso y desenvolvimiento, y á sancionar con su autoridad las prácticas regulares y constantes del buen uso ${ }^{164}$,

aunque a continuación se añada que «dentro de esos límites no impera un exclusivismo tal, que vede todo razonamiento» ${ }^{165}$.

Como puede comprobarse, los fundamentos de la corriente histórico-comparada impregnan la filosofía del Dictamen. En opinión de sus redactores, las modificaciones realizadas en la Gramática deben ser el resultado «de un buen estudio sobre el orígen, el desarrollo y las transformaciones de nuestra sintáxis, determinando cuales fueron sus elementos constitutivos, y la parte, esencial ó accidental, que en su formacion y constitucion tuvo cada uno de ellos» ${ }^{166}$.

159 Real Academia Española, ibíd.

160 Real Academia Española, ibíd.

161 R. Sarmiento, art. cit., pág. 218. Debido a la orientación positivista que tiene lugar con la llegada de la Filología Comparada, la Real Academia Española adopta un método más empírico al elaborar su doctrina gramatical, advertido principalmente en dos aspectos: $1^{\circ}$ ) en el registro que se hace de las leyes instintivas a que la lengua obedece, y $2^{\circ}$ ) en la descripción del estado real y presente del idioma (R. Sarmiento, art. cit., págs. 220-221).

162 Real Academia Española, Gramática..., 1870, pág. XII.

163 Real Academia Española, Gramática..., 1870, pág. XIII.

164 Real Academia Española, ibíd.

165 Real Academia Española, Gramática..., 1870, págs. XIII-XIV.

166 Real Academia Española, Dictamen..., pág. 13. 
Esta tendencia se acusa nuevamente en el proyecto de gramática cuando $\mathrm{J}$. E. Hartzenbusch, A. Fernández-Guerra y Orbe y P. F. Monlau, como colofón al apartado dedicado a la reforma de la Sintaxis en la $G R A E$, puntualizan que las reglas de la concordancia, el régimen y la construcción «suponen un cabal estudio analítico, histórico y comparativo, de la lengua. Así lo comprenderá sin duda la Academia, y lo llevará entendido su Comision redactora de la GRAMÁTICA» ${ }^{167}$.

15. La Comisión de Gramática considera que en el capítulo de las Oraciones la naturaleza de los juicios es el parámetro que debe regir su división. Así, proponen que se añadan después de las oraciones del verbo ser, «verbo sustantivo» ${ }^{168}$, las de estar, que en esencia difiere de aquel en «significar la atribucion de una manera transitoria y no habitual, diferencia filosófica y delicada que no conocen otras lenguas romances, la francesa por ejemplo» ${ }^{169} \mathrm{y}$ en presentar la particularidad de combinarse con «los gerundios activos y los participios pasivos formando oraciones especiales» ${ }^{170}$.

Por lo demás, en el Dictamen se enseña que toda oración se halla integrada por dos constituyentes inmediatos, un nombre y un verbo, o sea, por «un sujeto (expreso ó sobrentendido)» ${ }^{171}$ y por «un atributo» ${ }^{172}$. Esta es la oración simple. Pasa a ser compuesta «por la multiplicidad ó variedad de sujetos ó de atribuciones» ${ }^{173}$. Y es compleja «cuando el sujeto ó el atributo llevan incidentalmente algun desarrollo particular, pero siempre reducible á la oracion simple, fundamental y única» ${ }^{174}$. La división de las oraciones en simples, compuestas y complejas no es frecuente en los tratados gramaticales de la época. En la mayor parte de ellos se establece una división en simples y compuestas. Por lo que respecta a las de este último tipo, algunos autores de mediados del siglo XIX las conciben como las que tienen más de un sujeto, más de un verbo o más de un predicado; pero casi todos las caracterizan como las que necesitan más de un verbo en forma personal para expresar un pensamiento de forma completa.

Sin embargo, en la GRAE no se repara en exceso en la distinción entre oración simple y oración compuesta. En la edición de 1870, la primera en la que se trata de una forma más detallada esta división después de una lista clasifica-

167 Real Academia Española, Dictamen..., pág. 14.

168 Real Academia Española, ibíd.

169 Real Academia Española, ibíd.

170 Real Academia Española, ibíd.

171 Real Academia Española, ibíd.

172 Real Academia Española, ibíd. Este concepto de oración como expresión de un juicio, constituido por un sujeto y un predicado, cuenta en nuestra tradición con el precedente de C. Villalón, el Brocense, G. Correas, y en Francia con la Grammaire de Port-Royal, donde se identifica la construcción sujeto-predicado con el juicio o proposición.

${ }^{173}$ Real Academia Española, Dictamen..., pág. 14.

174 Real Academia Española, ibíd. 
toria de las oraciones, simplemente se indica que «la oracion que por sí hace sentido se llama simple; la que termina en otra se llama compuesta» ${ }^{175}$.

16. Por lo expuesto en las páginas precedentes a través del análisis de las propuestas de reforma que J. E. Hartzenbusch, A. Fernández-Guerra y Orbe y P. F. Monlau plasman en el Dictamen de la Comisión de Gramática para la actualización y mejora de la GRAE, se ha podido comprobar la confluencia que se da en el seno de la Real Academia Española de las teorías y métodos de las distintas corrientes de pensamiento linguístico de la época y el cambio de paradigma científico que se opera por aquellas fechas en nuestro país.

En este proyecto de planta de la edición de 1870 de la GRAE se combinan la tradición y la innovación, el logicismo de la Gramática General (en el concepto de oración, en las definiciones del artículo, el pronombre y la interjección, en la consideración de la conjunción como parte del discurso y no de la oración, en la equivalencia establecida entre el adverbio con la combinación preposición + nombre o en la denominación de artículo conjuntivo aplicada a la forma relativa que), el positivismo de la Gramática Histórico-Comparada (en determinados aspectos referentes al verbo, como la formación de los tiempos en las lenguas neolatinas, o en la propuesta de acometer el estudio de la Sintaxis de la Gramática con un enfoque analítico, histórico y comparativo de nuestra lengua al tratarse de las reglas de la concordancia, el régimen y la construcción) y el normativismo de la Gramática Tradicional (entre otros aspectos, en la definición de Gramática como arte de hablar y escribir correctamente o en la propuesta de incluir la Prosodia y la Ortografía en la GRAE, hecho que tiene lugar por primera vez en la edición de 1870).

Muchos aspectos doctrinales novedosos no se incluyen en la nueva edición reformada a pesar del fervor con el que son defendidos por algunos miembros de la Corporación en las Sesiones Académicas de 1861 y 1868 —otros que no figuran en el Dictamen son propuestos y aprobados en tales Sesiones e incorporados en la edición de 1870 de la GRAE, como la concesión del estatus de partes independientes de la oración al sustantivo y el adjetivo, incluidas con anterioridad en la categoría del nombre-, pues en todo momento la Corporación sigue una línea de eclecticismo que da como resultado una doctrina sólida y madura.

175 Real Academia Española, Gramática..., 1870, pág. 216. 